\title{
INFORMACION
}

\section{Transformaciones bioquímicas durante la fermentación de productos vegetales}

\author{
Por A. Montaño, A. de Castro y L. Rejano \\ Instituto de la Grasa y sus Derivados \\ Avda. Padre García Tejero, 4. 41012-Sevilla, España.
}

\section{RESUMEN}

Transformaciones bioquímicas durante la fermentación de productos vegetales

Se revisan los diferentes aspectos relacionados con la fermentacion de productos vegetales, desde los procesos de elaboración a los microorganismos responsables y los factores que afectan a su desarrollo. Se presentan, asimismo, las principales reacciones metabólicas de degradación de azúcares y ácidos orgánicos que tienen lugar en los medios de fermentación, asi como la influencia de éstas y otras reacciones sobre las caracteristicas sensoriales del producto elaborado. Finalmente, se citan algunas de las áreas de investigación en las que se considera habria que profundizar para una mayor valoración de los alimentos vegetales fermentados.

PALABRAS-CLAVE: Bacteria acidoláctica - Fermentación - Información (artículo) - Vegetal.

\section{SUMMARY}

Biochemical changes during vegetable products fermentation

Different topics dealing with vegetable products fermentation, from manufacturing to microorganisms, and their growth factors, are reviewed. The main pathways for sugar metabolism and degradation reactions of organic and amino acids are described, as well as their influence on sensorial characteristics of the final product. A thorough research on several areas is considered mandatory, in order to increase the value of fermented vegetable foods

KEY-WORDS: Fermentation - Information (paper) - Lactic acid bacteria - Vegetable.

\section{INTRODUCCION}

La mayoría de los frutos y vegetales son susceptibles de ser fermentados. Los productos típicos más investigados y que mayor difusión tienen en el mercado internacional son las aceitunas, pepinillos y coles (Fernández Diez, 1991). Como ejemplos de otros vegetales fermentados que se han estudiado en mayor o menor profundidad se pueden citar las zanahorias (Andersson et al., 1990), judias verdes (Chen et al., 1983b), tomates verdes (Laleye y Simard, 1981), remolacha (Andersson, 1984), apio (Bates, 1970), pimientos verdes (Fleming et al., 1983), alcaparras (Alvarruiz et al., 1990) y alcaparrones (Sánchez et al., 1992). Por otra parte, en los países orientales se elaboran otros vegetales fermentados que incorporan productos tales como los rábanos, nabos, coles de Bruselas, lechugas y guisantes (Fleming, 1982).

La fermentación en medio salino es uno de los métodos más antiguos de conservación de alimentos y aunque en el mundo occidental tiene un papel secundario con respecto a otras técnicas más modernas, como el tratamiento térmico, la congelación y la deshidratación, continúa siendo un importante método para conservar vegetales, incluso en los países más desarrollados, debido a las siguientes razones: (1) permite obtener productos con cualidades organolépticas muy apetecibles; (2) permite extender la temporada de elaboración de vegetales; y (3) requiere, comparativamente, un bajo gasto en instalaciones y consumo energético (Fleming, 1982). En contraste con las técnicas de conservación citadas anteriormente, la fermentación tiene como objetivo favorecer el desarrollo de determinados microorganismos.

El presente trabajo pretende dar una visión de los principios generales que rigen las fermentaciones de productos vegetales, prestando mayor atención a los principales cambios bioquímicos que tienen lugar durante las mismas y su repercusión sobre los atributos de calidad.

\section{PROCESO DE ELABORACION}

Antes de entrar a describir los diferentes aspectos relacionados con la fermentación conviene hacer un rápido examen del proceso general de elaboración de alimentos vegetales fermentados (Fig. 1). Previamente a la etapa de lavado, que no siempre se aplica en la industria, los vegetales pueden ser tratados de diversas formas, dependiendo de su naturaleza y del producto final deseado. Por ejemplo, a las coles se les quitan las hojas externas y el tronco central; en la preparación de aceitunas verdes aderezadas estilo español, los frutos se someten a un tratamiento alcalino con una solución diluida de hidróxido sódico para eliminar el intenso sabor amargo debido al glucósido oleuropeína.

Una vez realizadas estas operaciones iniciales, los vegetales se colocan en medio salino, donde ocurre la fermentación. Cuando ésta finaliza tiene lugar, en general, una etapa de escogido y clasificado para, finalmente, 
proceder al envasado del producto. La aplicación del tratamiento más adecuado para la conservación a largo plazo va a depender de las condiciones finales del producto fermentado. La pasterización es el procedimiento habitual, aplicándose la esterilización en el caso de que las características de $\mathrm{pH}$ del producto así lo aconsejen; la refrigeración a $5^{\circ} \mathrm{C}$ da resultados menos seguros que los anteriores.

El procedimiento de salado se puede realizar añadiendo la sal en forma sólida, como en el caso de la col, o en forma de salmuera, como en la mayoría de los demás vegetales. La concentración de sal utilizada varia ampliamente $(2-3 \%$ de $\mathrm{NaCl}$ en el caso de la col, $5-8 \%$ en pepinillos y $4-7 \%$ en aceitunas verdes) y depende, en gran medida, de la tendencia del producto a sufrir ablandamiento durante su permanencia en salmuera, originado por las enzimas pectinolíticas de origen microbiano o provenientes del propio vegetal. Así, mientras que un $2 \%$ de $\mathrm{NaCl}$ es suficiente para prevenir el ablandamiento en la col ácida, en los pimientos es necesario utilizar salmueras saturadas $(26 \% \mathrm{NaCl}$ aproximadamente) para mantener la textura.
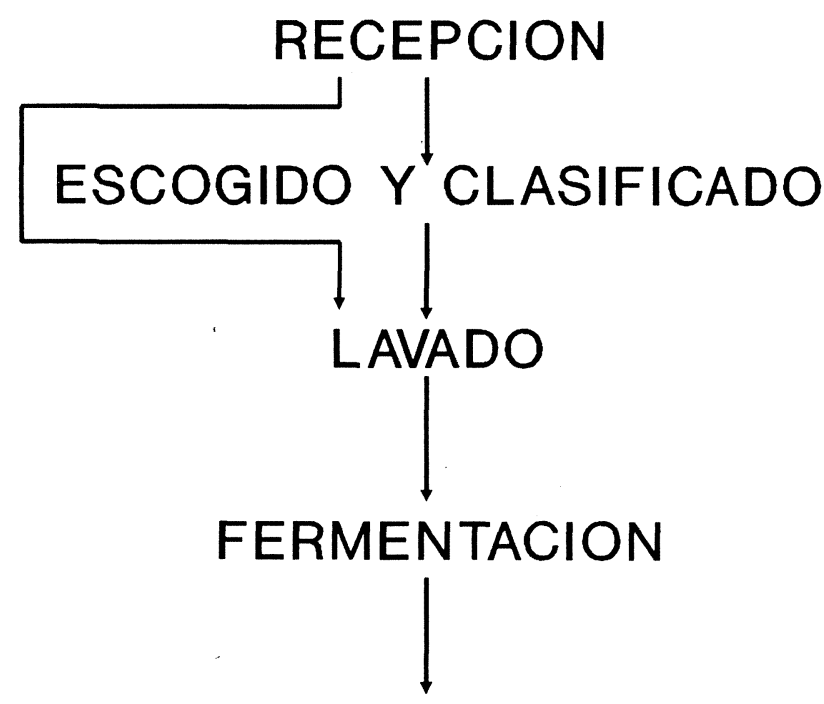

ESCOGIDO Y CLASIFICADO (PASTERIZACION)

Figura 1

Proceso general de elaboración de vegetales por fermentación.

\section{FERMENTACION}

La técnica convencional de fermentación de vegetales, que generalmente utiliza la industria, es bastante empirica y se basa en la fermentación espontánea debida a la carga microbiana que lleva el producto.

El crecimiento microbiano durante este proceso ha sido dividido en cuatro etapas bien definidas: (1) iniciación, que suele incluir el desarrollo de muchos microorganismos Gram-negativos y Gram-positivos presentes originalmente en los vegetales y en todo tipo de material en contacto con éstos; (2) fermentación primaria, que implica crecimiento de bacterias acidolácticas con o sin desarrollo de levaduras fermentativas; (3) fermentación secundaria, que se caracteriza por el crecimiento de levaduras fermentativas a partir de la materia fermentable que permanece después de que el desarrollo de las bacterias acidolácticas resulta inhibido por los bajos valores de $\mathrm{pH}$; (4) post-fermentación, que tiene lugar después de consumirse la materia fermentable y se caracteriza, en general, por el crecimiento de microorganismos oxidativos en la superficie de la salmuera cuando ésta se encuentra expuesta a la atmósfera (Fleming, 1982).

Las bacterias acidolácticas proliferan durante las fases de iniciación y fermentación primaria, dependiendo de su presencia en el producto original y de las condiciones químicas y ambientales bajo las cuales se mantiene el producto después de la adición de sal o salmuera. Las principales especies son: Leuconostoc mesenteroides, Pediococcus pentosaceus, Lactobacillus brevis y Lactobacillus plantarum, recogiéndose en la Tabla I las características principales de las mismas relacionadas con la fermentación.

Tabla 1

Principales características de las bacterias acidolácticas asociadas con las fermentaciones de productos vegetales

\begin{tabular}{|c|c|c|c|c|}
\hline & $\begin{array}{l}\text { Lactobacillus } \\
\text { plantarum }\end{array}$ & $\begin{array}{c}\text { Lactobacillus } \\
\text { brevis }\end{array}$ & $\begin{array}{l}\text { Pediococcus } \\
\text { pentosaceus }\end{array}$ & $\begin{array}{l}\text { Leuconostoc } \\
\text { mesenteroides }\end{array}$ \\
\hline $\begin{array}{c}\text { Mortologia } \\
\text { celular }\end{array}$ & $\begin{array}{c}\text { Bacilos en } \\
\text { cadena }\end{array}$ & $\begin{array}{c}\text { Bacilos en } \\
\text { cadena }\end{array}$ & $\begin{array}{c}\text { Cocos en pareja } \\
\text { y tétradas }\end{array}$ & $\begin{array}{c}\text { Cocos en parejas } \\
\text { y cadena }\end{array}$ \\
\hline $\begin{array}{c}\text { Temperatura } \\
\text { óptima }\left({ }^{\circ} \mathrm{C}\right)\end{array}$ & $30-35$ & 30 & $28-32$ & $20-30$ \\
\hline $\begin{array}{c}\text { Intervalo } \\
\text { aprox. de pH }\end{array}$ & $3.8-7,5$ & $3,8-7,5$ & $4,0-8,0$ & $4,5-8,0$ \\
\hline $\begin{array}{l}\text { Limite máx. } \\
\text { de } \mathrm{NaCl}(\%)\end{array}$ & 8.9 & $7-8$ & $8-9$ & 6.7 \\
\hline $\begin{array}{l}\text { Metabolismo } \\
\text { de glucosa }\end{array}$ & Homoláctico & Heteroláctico & Homoláctico & Heteroláctico \\
\hline $\begin{array}{l}\text { Ac. láctico } \\
\text { formado }\end{array}$ & $\mathrm{DL}$ & $D L$ & $\mathrm{DL}$ & $D$ \\
\hline
\end{tabular}

Un aspecto importante de las fermentaciones de alimentos vegetales, que las hace diferentes de otras (por ejemplo, de los productos lácteos), es que se trata de cuerpos sólidos inmersos en un medio líquido; en consecuencia, la velocidad de crecimiento microbiano viene 
influida por la salida de los solutos de carácter nutriente desde el producto hasta el líquido que lo rodea. Sin embargo, la fermentación no ocurre exclusivamente en la salmuera. Así, en pepinillos se ha podido comprobar mediante técnicas de microscopía electrónica que las bacterias acidolácticas también se desarrollan en el interior de los frutos después de su colocación en salmuera. No obstante, las levaduras no pueden entrar a través de los estomas debido a su mayor tamaño, lo que pone de manifiesto que la estructura histológica del producto llega a influir en la velocidad de fermentación y en el tipo de microorganismo involucrado (Daeschel et al., 1987).

Entre los diversos factores que influyen en el desarrollo y metabolismo de los microorganismos, los más adecuados para controlar el curso de las fermentaciones de vegetales son el nivel de acidez, la concentración de sal, la temperatura y el uso de cultivos iniciadores.

\subsection{Acidez}

El efecto inhibidor de los ácidos se ejerce tanto si éstos se producen como consecuencia de la fermentación o se añaden directamente al producto.

La liberación de ácidos por fermentación implica inhibir el crecimiento de bacterias sensibles que se encuentran en el vegetal de partida en mayor número que las bacterias acidolácticas. El ácido láctico es el mayoritario en el producto fermentado pero, como veremos, el ácido acético puede ser también importante dependiendo del desarrollo de bacterias heterofermentativas y del potencial redox del medio. Aunque el ácido láctico presenta un valor de pK inferior al del acético, lo que da lugar a valores inferiores de $\mathrm{pH}$, se ha demostrado que este último es más efectivo para la inhibición de mohos asociados con el ablandamiento de pepinillos en salmuera (Fleming et al., 1985).

La adición de ácidos inmediatamente después de la colocación de los vegetales en salmuera ha sido utilizada frecuentemente tanto en aceitunas verdes aderezadas (Rejano et al., 1977) como en pepinillos (Fleming, 1982) para dirigir el curso de la fermentación y como una etapa previa a la inoculación con un cultivo puro de lactobacilos.

\subsection{Concentración de sal}

Además de prevenir el ablandamiento de los vegetales, la concentración de $\mathrm{NaCl}$ regula también el tipo y extensión del crecimiento microbiano $y$, en consecuencia, la calidad y estabilidad del producto fermentado (Fleming y McFeeters, 1981). Así, L. mesenteroides es activo durante la fermentación primaria de la col, pero juega un papel menos importante en aceitunas y pepinillos debido, al menos en parte, a la mayor concentración de $\mathrm{NaCl}$ utilizada en estos últimos productos (Fleming et al., 1985). Dicha concentración no debe exceder el $8 \%(p / v)$ en salmuera con el fin de no retardar excesivamente el desarrollo de las bacterias acidolácticas.

\subsection{Temperatura}

Diferentes microorganismos pueden dominar una fermentación mixta dependiendo de la temperatura del pro- ceso. La producción de sauerkraut (col ácida) es particularmente sensible a este parámetro. Durante la fermentación primaria a $8 \circ 18^{\circ} \mathrm{C}$, predomina la especie L. mesenteroides, pero a altas temperaturas $\left(32 \circ 37^{\circ} \mathrm{C}\right)$ se acorta su período de crecimiento y se favorece el desarrollo de L. plantarum (Pederson y Albury, 1954).

\subsection{Uso de cultivos iniciadores ("starters")}

La experiencia existente sobre utilización de cultivos iniciadores o "starters" en otros alimentos fermentados, como derivados lácteos y cárnicos, bebidas alcohólicas, etc., indica que la ventaja de emplearlos no se limita sólo a disminuir la probabilidad de que se presenten alteraciones, sino que también implica la obtención de productos de mejor calidad organoléptica, más estables y homogéneos. Otra ventaja que puede buscarse al utilizar inóculos es reducir el tiempo de fermentación.

A pesar de lo anterior, en la actualidad, la industria de productos vegetales fermentados apenas hace uso de cultivos iniciadores por las razones siguientes: (1) la propia complejidad del proceso fermentativo, no conociéndose todavía en profundidad la importancia relativa de cada microorganismo; (2) en general, la fermentación natural por bacterias acidolácticas es bastante favorable, siempre que la materia prima se procese correctamente; (3) la utilización como inóculo de salmuera "madre" procedente de un recipiente en estado óptimo de fermentación, en lugar de cultivos puros, da normalmente excelentes resultados; (4) el tratamiento térmico es casi el único método efectivo para eliminar la flora natural que trae el vegetal, lo que facilitaría la fermentación por cultivo puro, pero ello modificaría otras características del producto, aparte de ser un tratamiento caro; (5) los recipientes de fermentación y, en general, las instalaciones de hoy en día, no son adecuados para la fermentación por medio de cultivos puros, ya que no mantienen las condiciones de aislamiento requeridas y no evitan el desarrollo de otros microorganismos; y (6) se carece de una cepa de bacteria acidoláctica con características tales que garanticen su eficacia como cultivo iniciador.

Las principales cualidades que tendría que poseer el inóculo óptimo para la obtención de productos vegetales fermentados son: (a) capacidad de metabolizar toda la materia fermentable presente en el menor tiempo posible; (b) producción de metabolitos que inhiban el desarrollo de otros microorganismos, al tiempo que den caracteristicas organolépticas aceptables y no sean tóxicos; (c) capacidad de crecimiento dentro de un amplio intervalo de concentración $\mathrm{NaCl}, \mathrm{pH}$ y temperatura; (d) resistencia a inhibidores, tanto procedentes del fruto como de otros microorganismos; (e) resistencia a bacteriófagos; y ( $f$ ) mínimos requerimientos nutricionales.

Posiblemente, si se dispusiera de una cepa microbiana con estas características, su aplicación sí sería claramente beneficiosa. A falta de ello, el procedimiento más económico y práctico consiste en provocar una fermentación dirigida que sea realizada por una o más especies conocidas con características bioquímicas adecuadas. Cuando se sigue este procedimiento, otros microorganismos que puedan asimismo desarrollarse no van a tener una influencia apreciable sobre el producto final. 


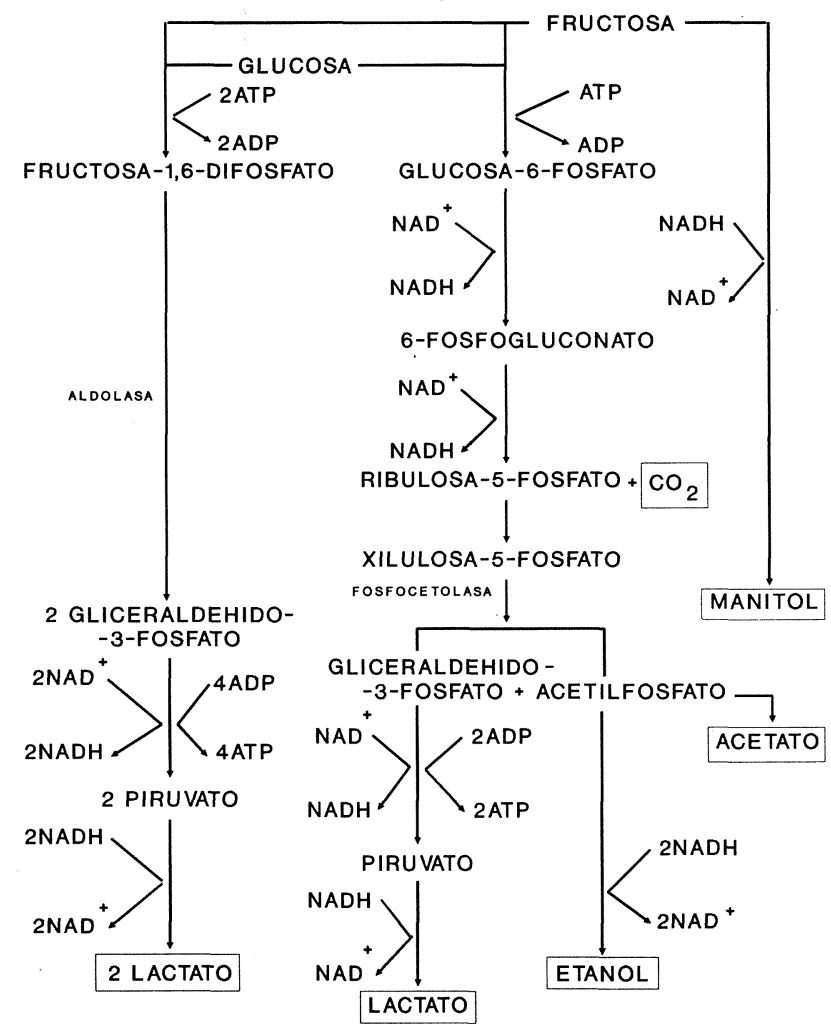

RUTA GLUCOLITICA RUTA DEL FOSFOGLUCONATO

Figura 2

Principales rutas metabólicas de fermentación de azúcares por bacterias acidolácticas.

\section{RUTAS METABOLICAS IMPORTANTES EN LAS FERMENTACIONES DE PRODUCTOS VEGETALES}

Se exponen seguidamente las principales rutas metabólicas que pueden utilizar los diferentes microorganismos mencionados y los productos mayoritarios que originan.

\subsection{Metabolismo de los azúcares}

Los principales carbohidratos existentes en la mayoría de los vegetales son glucosa, fructosa y sacarosa. Las pentosas libres no suelen estar presentes en cantidades suficientes como para ser importantes en las fermentaciones. El manitol puede ser uno de los sustratos mayoritarios en ciertas circunstancias. Por ejemplo, en aceitunas verdes se han encontrado cantidades del orden del $7 \%$, referido a peso seco, que disminuye al avanzar la maduración (Vázquez Roncero, 1965).

\subsubsection{Bacterias acidolácticas}

Las bacterias acidolácticas involucradas en las fermentaciones de vegetales pueden metabolizar los azúcares siguiendo dos rutas importantes (Fig. 2).

Las bacterias homofermentativas $u$ homolácticas metabolizan las hexosas a través de la ruta glucolítica o via de Embden-Meyerhof, para dar ácido láctico casi exclusivamente como producto final. Se producen dos moles de ATP por mol de hexosa fermentada y no hay producción neta de poder reductor ya que el NADH producido en la transformación de la triosafosfato a piruvato se consume posteriormente en la reducción del piruvato a lactato. La reacción global es:

$$
\text { Glucosa (o Fructosa) } \rightarrow 2 \text { Láctico }
$$

Las bacterias heterofermentativas o heterolácticas, al carecer de la enzima aldolasa (EC 4.1.2.13), producen, a partir de un mol de glucosa, un mol de ácido láctico, un mol de etanol (o ácido acético) y un mol de anhídrido carbónico (Kandler y Weiss, 1986). En esta ruta, denominada ruta del 6-fosfogluconato, se produce un mol de ATP por mol de hexosa fermentada. También difiere de la glucolisis en que se originan tres moles de $\mathrm{NADH}$. Para recuperar el equilibrio redox, un mol se oxida en la etapa de reducción del piruvato y, si no existen aceptores de electrones alternativos, el acetilfosfato se reduce a etanol oxidándose los otros dos moles de $\mathrm{NADH}$; si existen aceptores alternativos se forma ácido acético como producto final. La fructosa también puede ser metabolizada a través de la ruta heterofermentativa de forma análoga a la glucosa, pero también puede funcionar como una aceptor de electrones adecuado llevando a cabo la oxidación del NADH; como resultado, una gran parte de la fructosa se reduce a manitol. Se tienen ahora las siguientes reacciones globales:

\section{Glucosa $\rightarrow$ Láctico + Etanol $+\mathrm{CO}_{2}$ \\ 3 Fructosa $\rightarrow 2 \mathrm{Manitol}+$ Láctico + Acético $+\mathrm{CO}_{2}$}

L. plantarum ha sido clasificado como un microorganismo homoláctico facultativo debido a que posee todas las enzimas necesarias para realizar ambas rutas. Además, se ha comprobado que puede metabolizar el manitol para dar ácido láctico como producto mayoritario, si bien es necesaria la presencia de un aceptor de electrones adecuado en condiciones anaeróbicas (McFeeters y Chen, 1986).

Las bacterias acidolácticas pueden producir uno o los dos esteroisómeros, $L$ y $D$, del ácido láctico. L. mesenteroides produce sólo el isómero $D$, mientras que $L$. plantarum. $L$. brevis y $P$. pentosaceus forman mezclas de ambos isómeros. Su producción se debe a las respectivas enzimas, D-lactato deshidrogenasa (EC 1.1.1.28) y Llactato deshidrogenasa (EC 1.1.1.27), que reducen el piruvato a lactato; de hecho, cuando se forma la mezcla, ambas se encuentran presentes aunque normalmente con distinta actividad, lo que da lugar a un exceso de uno de los isómeros y raramente resulta una mezcla racémica (Fleming et al., 1985). Por otro lado, aunque los dos son metabolizados normalmente por los mamíferos, el D lo hace más lentamente y, en consecuencia, se considera como el isómero no fisiológico. Ello llevó al Comité de Expertos de la FAO/WHO, en el año 1974, a recomendar que este isómero fuera eliminado de alimentos para niños. La importancia del tema ha hecho que se investigue acerca de la elaboración de "sauerkraut" o col ácida que 
contenga únicamente el ácido L-láctico, llegándose a aislar la especie L. bavaricus, que forma exclusivamente este isómero, y que ha sido ya utilizada para la preparación de este producto a escala industrial (Eden-Waren $\mathrm{GmbH}, 1976$ ).

Es interesante considerar las diferentes caracteristicas que, teóricamente, se obtendrían al utilizar como iniciadores microorganismos homo o heterofermentativos. Las consecuencias de emplear un homofermentativo son bastante simples: las hexosas se convierten eficientemente en dos moles de ácido láctico, lo que puede ser importante cuando existe poca cantidad de azúcar en el medio. Los microorganismos heterofermentativos, por su parte, conducen a más posibilidades de fermentación; primero, se produce gran cantidad de $\mathrm{CO}_{2}$ lo que puede ser perjudicial en algunos productos, como los pepinillos, susceptibles a la formación de huecos interiores, y segundo, se obtiene una distribución de productos más compleja, ya que, además del ácido láctico, se origina ácido acético, etanol y manitol.

La producción ácida a partir de una determinada cantidad de azúcar es generalmente menor en una fermentación heteroláctica que en una homoláctica. Como ejemplo, si consideramos el caso en que se fermenten iguales cantidades de glucosa y fructosa, y la fructosa se reduce cuantitativamente a manitol, se tendría lo siguiente:

a) Bacterias homofermentativas

$$
\begin{aligned}
& 2 \text { Glucosa } \rightarrow 4 \text { Láctico } \\
& 2 \text { Fructosa } \rightarrow 4 \text { Láctico }
\end{aligned}
$$

b) Bacterias heterofermentativas

2 Glucosa $\rightarrow 2$ Láctico + 1 Acético + 1 Etanol + 2 CO2 2 Fructosa $\rightarrow 2$ Manitol

Es decir, en el caso de una fermentación heteroláctica se producen únicamente 3 moles de ácido, mientras que en la homoláctica se originan 8 . En la práctica, sin embargo, se comprueba que las estequiometrias de las reacciones en fermentaciones de productos vegetales no siempre se ajustan a las teóricas y que, incluso, algunas bacterias acidolácticas se comportan de manera totalmente inesperada (Chen et al., 1983a).

Resulta bastante útil el construir los correspondientes balances que den cuenta de la distribución de los átomos de carbono, hidrógeno y oxígeno entre sustratos y productos, lo que ayuda a reconocer situaciones en las que se echan en falta cantidades importantes de los anteriores compuestos. Esto puede ser utilizado como orientación o guía en la búsqueda de reacciones adicionales llevadas a cabo por las bacterias acidolácticas. Como ejemplo, en la Tabla II se recogen los resultados obtenidos por Fleming et al. (1988) en dos experiencias de fermentación dirigida de pepinillos a dos niveles de concentración salina de la salmuera, utilizándose como inóculo un cultivo puro de L. plantarum. El hecho de que los milimoles de ácido láctico producidos por milimol de hexosa fermentada se aproxime bastante al valor teórico de 2,0, indica que la fermentación transcurre principalmente por la ruta homofermentativa. Los autores sugie-
Tabla II

Balances de fermentación para pepinillos en salmuera

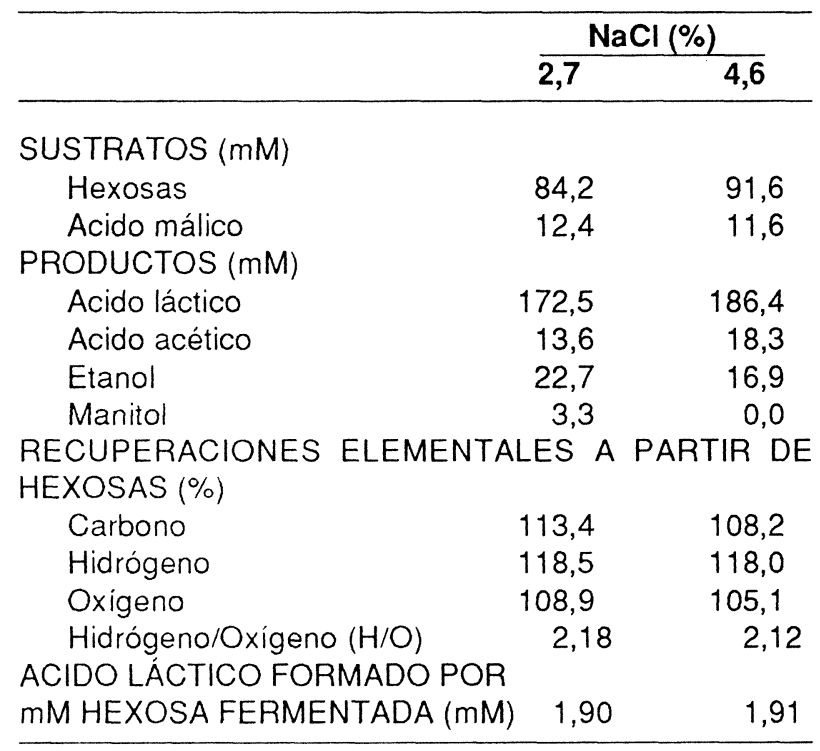

Datos tomados de Fleming et al. (1988).

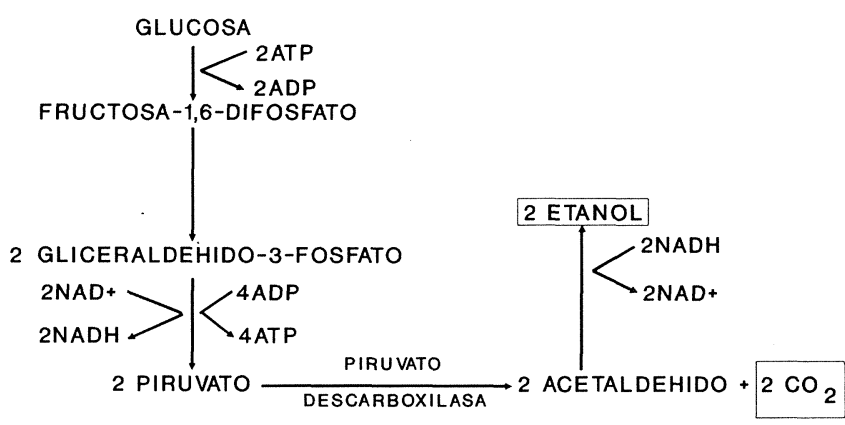

SEGUNDA FORMA DE FERMENTACION

$\mathrm{GLUCOSA}+\mathrm{HSO}_{3}^{-} \longrightarrow \mathrm{GLICEROL}+\mathrm{ACETALDEHIDO} . \mathrm{HSO}_{3}+\mathrm{CO}_{2}$

TERCERA FORMA DE FERMENTACION

$2 \mathrm{GLUCOSA} \underset{\text { MEDIO ALCALINO }}{\longrightarrow} 2 \mathrm{GLICEROL}+$ ACETATO + ETANOL + $2 \mathrm{CO}_{2}$

Figura 3

Metabolismo de la glucosa por levaduras fermentativas

ren, como una posible explicación de que los porcentajes de recuperación de C obtenidos sobrepasen el 100\%, que parte del material de la páred celular se transforma en alguno de productos cuantificados. El descubrimiento de una cepa de $L$. mesenteroides con actividad pectinolítica (Juven et al., 1985), capaz de formar ácido galacturónico, el cual puede ser posteriormente fermentado por 
otras bacterias acidolácticas, podría apoyar esta hipótesis.

\subsubsection{Levaduras}

Las levaduras fermentativas pueden estar presentes durante la fermentación primaria y son los microorganismos predominantes en la fermentación secundaria de pepinillos y aceitunas; sin embargo, en el caso de la col su desarrollo es bastante escaso, lo que se atribuye en parte a que las bajas concentraciones de sal utilizadas favorecen, especialmente, a las bacterias acidolácticas (Fleming, 1982).

Bioquímicamente, las levaduras metabolizan la glucosa siguiendo la ruta glucolítica hasta la formación de piruvato (Fig. 3) pero, a diferencia con las bacterias acidolácticas y animales, las levaduras poseen la enzima piruvato descarboxilasa, que actúa sobre el piruvato para dar $\mathrm{CO}_{2}$ y acetaldehido; a continuación, el acetaldehido se puede reducir a etanol con oxidación del NADH a NAD+. En total se originan dos moles de ATP por mol de glucosa fermentada.

Existen además, como se recoge en la Fig. 3, otras formas de fermentación de la glucosa que dependen de la adición al medio de diversos agentes, como bisulfito o álcalis, y en las que se producen cantidades significativas de glicerol (Rose, 1969).

\subsubsection{Otras bacterias}

Existen otros grupos de bacterias, distintas de las homolácticas, que también pueden seguir la ruta glucolítica, diferenciándose únicamente en los productos finales

Tabla III

Otras fermentaciones bacterianas de los azúcares que proceden a través de la ruta glucolítica

\begin{tabular}{lll}
\hline Clase de fermentación & $\begin{array}{l}\text { Productos principales } \\
\text { del ácido pirúvico }\end{array}$ & Bacterias \\
& $\begin{array}{l}\text { Acido láctico } \\
\text { Acido acético } \\
\text { Acido succínico } \\
\text { Ac. Fórmico }\left(\mathrm{CO}_{2} \mathrm{y} \mathrm{H}_{2}\right)\end{array}$ & Escherichia \\
& Etanol & \\
\hline Butanodiolica & Idem anterior, pero & Enterobacter \\
además 2,3-Butanodiol & \\
\hline Butírica & $\begin{array}{l}\text { Acido Butírico } \\
\text { Acido Acético } \\
\mathrm{CO}_{2} \text { y } \mathrm{H}_{2}\end{array}$ & Clostridium \\
\hline Acetona-Butanolica & $\begin{array}{l}\text { Idem anterior, pero } \\
\text { además Butanol, Etanol, } \\
\text { Acetona, Isopropanol. }\end{array}$ & Clostridium \\
\hline
\end{tabular}

que originan a partir del ácido pirúvico. En la Tabla III se recogen las diferentes fermentaciones que llevan a cabo por esta vía algunos géneros de bacterias Gram-negativas y Gram-positivas que se han encontrado, frecuentemente, durante la etapa de iniciación en fermentaciones naturales de productos vegetales. Las bacterias del género Propionibacterium, que realizan la llamada fermentación propiónica de los azúcares, no son importantes durante dicha etapa. Su interés principal radica en la

\section{Tabla IV}

Descarboxilaciones de ácidos orgánicos y aminoácidos por bacterias acidolácticas.

\begin{tabular}{|c|c|c|}
\hline & & Reacción \\
\hline Acido málico & $\rightarrow$ & Acido láctico $+\mathrm{CO}_{2}$ \\
\hline Acido citrico & $\rightarrow$ & Acido acético + acido piruvico $+\mathrm{CO}_{2}$ \\
\hline 2 Acido tartárico & $\rightarrow$ & Acido láctico + acido acético $+3 \mathrm{CO}_{2}$ \\
\hline 3 Acido tartárico & $\rightarrow$ & 2 Acido acético + acido succinico $+4 \mathrm{CO}_{2}$ \\
\hline Arginina & $\rightarrow$ & Ornitina $+\mathrm{NH}_{3}+\mathrm{CO}_{2}$ \\
\hline Acido glutámico & $\rightarrow$ & Acido $\alpha$-Aminobutírico $+\mathrm{CO}_{2}$ \\
\hline Histidina & $\rightarrow$ & Histamina $+\mathrm{CO}_{2}$ \\
\hline Tirosina & $\rightarrow$ & Tiramina $+\mathrm{CO}_{2}$ \\
\hline
\end{tabular}

facultad que tienen de metabolizar anaeróbicamente el ácido láctico, como se comenta en el siguiente apartado.

\subsection{Metabolismo de ácidos orgánicos y aminoá- cidos}

En la Tabla IV se muestran algunos de los compuestos que pueden ser descarboxilados por bacterias acidolácticas. Las degradaciones del ácido málico y del cítrico son las más importantes debido a la facilidad de dichos microorganismos para metabolizarlos y a la presencia de estos ácidos en cantidades apreciables en la mayoría de los vegetales. La enzima que cataliza la reacción del ácido málico para dar láctico recibe el nombre de enzima maloláctica y puede ser sintetizada por la mayoría de las cepas de bacterias acidolácticas. El ácido cítrico, por otra parte, puede ser degradado por muchas especies, dando lugar en un primer paso a los ácidos acético y oxalacético por acción de la enzima citratoliasa (EC 4.1.3.6.); a continuación, el ácido oxalacético se descarboxila obteniéndose ácido pirúvico y $\mathrm{CO}_{2}$ (Fleming et al., 1985).

Por otra parte, el ácido tartárico, mayoritario en el mosto de uva, se ha detectado también en vegetales ( $p$. ej., aceitunas verdes) pero siempre en cantidades poco importantes. El mecanismo de degradación de este ácido es diferente según sea metabolizado por una bacteria homo o heterofermentativa. En el primer caso se forma ácido acético, ácido láctico y $\mathrm{CO}_{2}$, mientras que en el segundo se produce ácido acético, $\mathrm{CO}_{2}$ y cantidades minoritarias de ácido succínico (Radler, 1975).

Además de la fermentación propiónica ya mencionada, la mayoría de las bacterias del género Propionibacterium son capaces de fermentar el ácido láctico para dar los mismos productos del metabolismo de los azúcares, 
es decir, ácido propiónico, ácido acético y $\mathrm{CO}_{2}$. Esta fermentación es bastante normal en el caso de las aceitunas verdes aderezadas, constituyendo lo que se ha dado en llamar "cuarta fase de la fermentación", la cual tiene lugar al final de la fermentación láctica, una vez que se han agotado los azúcares (Rodríguez de la Borbolla y Rejano Navarro, 1981). Debido a la menor constante de disociación de los ácidos acético y propiónico, en relación a la del láctico, se produce un incremento de $\mathrm{pH}$ que puede variar desde una o dos décimas, cuando el desarrollo es escaso, hasta más de cuatro décimas en caso de un crecimiento abundante. Si esto ocurre nos encontramos que el $\mathrm{pH}$ puede superar el valor crítico de 4,5 unidades, aumentando así la probabilidad de que se altere un producto considerado estable. Con el fin de inhibir el desarrollo de las bacterias propiónicas, es práctica habitual, una vez concluida la fermentación, incrementar el contenido de $\mathrm{NaCl}$ de la salmuera hasta superar el $8 \%$ en el equilibrio.

Otros microorganismos que normalmente se desarrollan durante la fermentación de vegetales, y que pueden suponer también un riesgo de posteriores alteraciones, son las levaduras oxidativas, ya que forman velos o películas en la superficie de los fermentadores consumiendo el ácido láctico formado durante el proceso fermentativo; por tanto, se eleva así el pH de la salmuera con el consiguiente peligro de desarrollo de microorganismos indeseables. No obstante, y al contrario de las bacterias propiónicas, esto solamente se produce en condiciones aerobias, de ahí la importancia de disponer de recipientes con cierres anaerobios adecuados durante todo el proceso de fermentación y posterior conservación. Con ello se evita al mismo tiempo el desarrollo de otras especies de hongos y bacterias, que pueden crecer también en las superficies de las salmueras, y que por su alta actividad pectinolítica dan lugar a problemas de ablandamiento del producto.

En relación con las descarboxilaciones de aminoácidos, apenas se han realizado estudios en productos vegetales fermentados. Cabe mencionar la determinación de histamina, formada a partir del aminoácido histidina, en coles, aceitunas y pepinillos (Taylor et al., 1978; Iñigo y Abad, 1983 a, b). Al parecer, bacterias acidolácticas del género Pediococcus se encuentran implicadas en esta reacción. En cualquier caso, los niveles de histamina encontrados están muy por debajo del valor mínimo considerado perjudicial para la salud.

\section{INFLUENCIA DE LA FERMENTACION SOBRE LAS CARACTERISTICAS SENSORIALES}

Es indudable que los distintos compuestos formados como resultado del metabolismo de los diferentes sustratos citados van a contribuir en mayor o menor medida al flavor de los vegetales fermentados. Quizás, el caso más claro lo constituye la col ácida, en la que el crecimiento de $L$. mesenteroides durante las primeras etapas es deseable, ya que forma, relativamente, grandes cantidades de ácido acético. De hecho, la fermentación se hace a baja temperatura $\left(18^{\circ} \mathrm{C}\right.$ o inferior $)$ para favorecer el desarrollo de este microorganismo. A temperaturas superio- res predomina $L$. plantarum lo que da lugar a menores cantidades de ácidos volátiles; el producto obtenido presenta un flavor ácido agudo a diferencia del obtenido a bajas temperaturas, de flavor más suave.

Aunque se han publicado algunos trabajos sobre análisis de componentes volátiles responsables del aroma en aceitunas (Fleming et al., 1969) y pepinillos (Aurand et al., 1965) se desconoce cuál es la contribución relativa de cada uno de estos componentes, así como su evolución a lo largo de la fermentación. Uno de los pocos trabajos completos publicados al respecto es el de Karki et al. (1983), quienes realizan el estudio con una preparación típica oriental, mezcla de diversos vegetales fermentada por bacterias acidolácticas, conocida como Gundruk.

Además de su efecto conservador y de su influencia sobre el flavor, los procesos fermentativos producen cambios en otros atributos de calidad tales como la textura y el color, lo que hace que los productos fermentados sean, en general, más apetitosos y digeribles.

En relación con la textura, generalmente no se dan grandes cambios durante la fermentación si ésta transcurre normalmente y las condiciones de anaerobiosis son las adecuadas. Pero si la elaboración no es correcta puede llegar a representar un serio problema. El ablandamiento ha sido la causa de grandes pérdidas económicas para el sector industrial, aunque gracias a las investigaciones realizadas se conoce hoy día el origen de esta alteración y los medios para prevenirla (Fleming, 1982). Las disminuciones de textura se atribuyen a la modificación de los constituyentes pécticos debido principalmente a la acción de enzimas pectinolíticas implicadas én el mecanismo biológico de degradación. Tanto en pepinillos como en aceitunas negras, se ha puesto de manifiesto que la adición de sales de calcio a la salmuera inicial consigue reducir significativamente las pérdidas de textura que se producen durante la fermentación (Garrido et al., 1986; Buescher et al., 1979). En el caso de los pepinillos, se continúa investigando a nivel básico para conocer precisamente el tipo de interacción entre el ión $\mathrm{Ca}^{++}$y los polisacáridos de la pared celular que explique su efecto positivo sobre la textura (McFeeters y Fleming, 1991). Por otro lado, se ha encontrado que altas concentraciones de ácido láctico pueden dar lugar a ablandamiento en vegetales fermentados. Así, Etchells et al. (1966) encuentran que las aceitunas verdes aderezadas fermentadas por $L$. plantarum presentan peor textura que las fermentadas por $L$. mesenteroides. Como un posible mecanismo, se ha sugerido que el ácido láctico interacciona con el calcio de las sustancias pécticas, dando lugar a las pérdidas de textura observadas (Bell et al., 1972).

El color de un alimento es asimismo un factor determinante para su aceptabilidad, ya que produce en el consumidor potencial la primera impresión de aceptación o rechazo. Pepinillos y aceitunas verdes son los vegetales fermentados más investigados en este aspecto (Jones et al., 1962; Mínguez Mosquera et al., 1989). La fermentación láctica trae como consecuencia la transformación de algunos de los pigmentos responsables del color (clorofilas a y b y los carotenoides violaxanteno y neoxanteno) 
debido al pH ácido del medio, mientras que otros permanecen inalterados durante el proceso (luteína y B-caroteno). Ello origina los cambios de color observados: desde verde a un verde amarillento en las aceitunas aderezadas y desde un verde-brillante a un verde oscuro en pepinillos.

\section{AREAS DE INTERES PARA FUTURAS INVESTIGACIONES}

La utilización de cultivos iniciadores es una técnica atractiva para la obtención de productos vegetales fermentados de características óptimas. Un mayor desarrollo de los sistemas de transferencia genética en bacterias acidolácticas permitiría que las fermentaciones llevadas a cabo por cultivos de tales bacterias fueran más predecibles (Daeschel et al., 1987). Para favorecer la implantación del inóculo sobre la flora natural podría ser de utilidad el uso de bacterias acidolácticas productoras de bacteriocinas (compuestos antimicrobianos con propiedades antagónicas frente a otras bacterias filogenéticamente próximas). Parte de las investigaciones que se llevan a cabo en la actualidad se centran en el aislamiento, a partir de salmueras de fermentación de vegetales, de cepas productoras de bacteriocinas y estudio de las características físico-químicas, espectro de acción y cinética de producción de tales compuestos (Jiménez-Diaz et al., 1990; Harris et al., 1992).

Por otro lado, como se ha comentado con anterioridad, se han realizado pocos estudios sobre la influencia de la fermentación en el flavor de los vegetales. Sería interesante investigar sobre la formación de los compuestos responsables con el fin de fijar la calidad del producto tradicional y desarrollar procedimientos mejorados de fermentación dirigida.

Por último, otro área que podría ser de interés es el estudio de los vegetales fermentados desde un punto de vista nutricional. Los vegetales se consideran generalmente como nutritivos y esenciales en dietas equilibradas. Existen, sin embargo, muy pocos trabajos acerca de cómo influye el proceso de fermentación en su valor nutritivo. Al parecer, la fermentación láctica dirigida con las bacterias acidolácticas utilizadas más frecuentemente ( $p$. ej., L. plantarum) no consiguen mejoras importantes en el valor nutritivo del producto sino que, por el contrario, originan pérdidas significativas de algunas vitaminas, lo que se explica teniendo en cuenta los requerimientos nutricionales de estos microorganismos. Se sabe, sin embargo, que ciertas bacterias son capaces de producir vitamina B12, de la cual carecen los vegetales frescos, lo que podría ser particularmente de interés en dietas vegetarianas (Ro et al., 1979). Por selección, adaptación o ingeniería genética de microorganismos, podría conseguirse en un futuro la producción de otros nutrientes esenciales, lo que ayudaría a retener y probablemente a realzar la importancia de la fermentación como medio para conservar productos vegetales en los países desarrollados.

\section{BIBLIOGRAFIA}

1. Alvarruiz, A.; Rodrigo, M.: Miquel, J.; Giner, V.; Feria, A. y Vila, R. (1990)."Influence of brining and packing conditions on product quality of capers". $J$. Food Sci. 55, 196-198.

2. Andersson, R.E. (1984).- "Characteristics of the bacterial flora isolated during spontaneous lactic acid fermentation of carrots and red beets".- Lebensm.- Wiss. u.- Technol. 17, 282-286.

3. Andersson, R.E.; Eriksson, C.E.; Salomonsson, A.- C. y Theander, O. (1990). - "Lactic acid fermentation of fresh and stored carrots: chemical, microbial and sensory evaluation of products".- Lebensm.- Wiss. u.- Technol. 23, 34-40.

4. Aurand, L.W.; Singleton, J.A.; Bell, T.A. y Etchells, J.L. (1965).- "Identification of volatile constituents from pure-culture fermentations of brined cucumbers".- J. Food Sci. 30, 288-295

5. Bates, R.P. (1970).- "Lactic acid fermentation of outer celery petioles".- J. Food Sci. 35, 476-478.

6. Bell, T.A.; Turney, L.J. y Etchells, J.L. (1972).- "Influence of different organic acids on the firmness of fresh-pack pickles".- J. Food Sci. 37, 446-449.

7. Buescher, R.W.; Hudson, J.M. y Adams, J.R. (1979).- "Inhibition of polygalacturonase softening of cucumber pickles by calcium chloride". $J$. Food Sci. 44, $1.786-1.787$

8. Chen, K.-H.; MCFeeters, R.F. y Fleming, H.P. (1983a).- "Fermentation characteristics of heterolactic acid bacteria in green bean juice".- J. Food Sci. $48,962-966$

9. Chen, K.-H.,; McFeeters, R.F. y Fleming, H.P. (1983b).- "Complete heterolactic acid fermentation of green beans by Lactobacillus cellobiosus".- J Food Sci. 48, 967-971.

10. Daeschel, M.A.; Andersson, R.E. y Fleming, H.P. (1987).- "Microbial ecology of fermenting plant material".- FEMS Microbial. Reviews 46, 357-367.

11. Eden-Waren $\mathrm{GmbH}$ (1976).- "Lactobacillus bavaricus recovery in a pure culture and use for lactic acid termentation of plant material".- German Federal Republic Patent Application 2, 440, 516.

12. Eichells, J.L.: Borg, A.F.: Kittel, I.D.; Bell, T.A. y Fleming, H.P. (1966).- "Pure culture fermentation of green olives".- Appl. Microbiol. 14, 1.027-1.041.

13. Fernández Díez, M.J. (1991).- "Frutos y vegetales aderezados".- Grasas y Aceites $42,74-83$

14. Fleming, H.P. (1982).- "Fermented vegetables" en "Economic Microbiology Fermented Foods". Vol. 7, p. 227.- A.H. Rose (Ed.).- Academic Press Inc., New York.

15. Fleming, H.P. y McFeeters, R.F. (1981).- "Use of microbial cultures: vegetable products".- Food Technol. 35, 84-88.

16. Fleming, H.P.; Etchells, J.L. y Bell, T.A. (1969).- "Vapor analysis of fermenred Spanish-type green olives by gas chromatography".- J. Food Sci. 34, 419-422.

17. Fleming H.P. McFeeters, R.F y Daeschel, M.A. (1985).- "The lactobacilli, pediococci, and leuconostocs: vegetable products" en "Bacterial starter cultures for loods".- S. E. Gilliland (Ed.).- CRC Press, Florida.

18. Fleming, H.P.; MCFeeters, R.F.; Thompson, R.L. y Sanders, D.C. (1983)."Storage stability of vegetables fermented with pH control".- J. Food Sci. 48 975-981.

19. Fleming, H.P.; McFeeters, R.F.; Daeschel, M.A.; Humphries, E.G. y Thomp son, R.L. (1988).- "Fermentation of cucumbers in anaerobic tanks".- J. Food Sci. $53,127-133$

20. Garrido, A.: Minguez, M.1.: Durán, M.C. y Garcia, P. (1986).- "Efecto de la utilización de calcio en la elaboración de diferentes tipos de aceitunas negras de mesa" - Simposio Internacional "Los aditivos en la industria agroalimentaria". Madrid.

21. Harris, L.J.; Fleming, H.P. y Klaenhammer, T.R. (1992).- "Novel paired starter culture system for sauerkraut, consisting of a nisin-resistant Leuconostoc mesenteroides strain and a nisin-producing Laclococcus lactis strain".-Appl. Environ. Microbiol. 58, 1.484-1.489.

22. Iñigo, R.M. y Abad, F.B. (1983a).- "Fermentación y nivel de histamina en aceitunas verdes".- Alimentaria 141, 33-41.

23. Iñigo, R.M. y Abad, F.B. (1983b).-- "Contenido en histamina en pepinillos encurtidos".- Alimentaria 147, 47-50

24. Jiménez-Diaz, R.; Piard, J.C.; Ruiz-Barba, J.L. y Desmazeaud, M.J. (1990)."Isolation of a bacteriocin-producing Lactobacillus plantarum strain from a green olive termentation".- Tercer Simposio sobre "Bacterias Acidolácticas (Genética, Metabolismo y Aplicaciones)".- Wageningen, Holanda.

25. Jones, I.D.; White, R.C. y Gibbs, E. (1962).- "Some pigment changes in cucumbers during brining and brine storage".- Food Technol. 19, 96-102.

26. Juven, B.J.; Lindner, P. y Weisslowicz, H. (1985).- "Pectic degradation in 
plant material by Leuconostoc mesenteroides'.- J. Appl. Bacteriol. $58,533-$ 538

27. Kandler, O. y Weiss, N. (1986).-- "Regular, nonsporing Gram-positive rods" en "Bergey's Manual of Systematic Bacteriology", vol. 2.- P.H.A. Sneath, N.S. Mair, M.E. Sharpe y J.G. Holt (Ed.).- Williams and Wilkins, Baltimore.

28. Karki, T.; Itoh, H. y Kozaki, M. (1983).- "Chemical changes occuring during Gundruk fermentation. Pan II-2. Flavour components".- Lebensm.- Wiss. u.Technol. 16, 203-208

29. Laleye, L.C. y Simard, R.E. (1981).- "Preservation of green tomato by lactic acid termentation" en "Advances in biotechnology. Vol. II. Fuels, chemicals, foods and waste treatment", p. 497.- M. Moo-Young y C.W. Robinson (Ed.).- Pergamon Press Lid., Oxiord.

30. McFeeters, R.F. y Chen, K.-H. (1986).- "Utilization of electron acceptors for anaerobic mannitol metabolism by Lactobacillus plantarum. Compounds which serve as electron acceptors".- Food Microbiol. 3, 73-81.

31. McFeeters, R.F. y Fleming, H.P. (1991).- "pH effect on calcium inhibition of softening of cucumber mesocarp tissue".- J. Food Sci. 56, 730-732.

32. Minguez Mosquera, M.l.; Garrido Fernández, J. y Gandúl Rojas, B. (1989)."Pigment changes in olives during fermentation and brine storage".- J. Agric. Food Chem. 37, 8-11.

33. Pederson, C.S. y Albury, M.N. (1954).- "The influence of salt and temperature on the microflora of sauerkraut fermentation".- Food Technol. 8, 1-5.

34. Radler, F. (1975). - "The metabolism of organic acids by lactic acid bacteria" en "Lactic acid bacteria in beverages and food".- J.G. Carr, C.V. Cutting y G.C. Whiting (Ed.).-Acadernic Press, London.

35. Rejano Navarro, L.; González Cancho, F. y Borbolla y Alcalá, J.M.R. (1977). - "Estudios sobre el aderezo de aceitunas verdes. XXIV. Nuevos ensayos sobre el control de la fermentación".- Grasas y Aceites 28, 255265

36. Ro, S.L.; Woodburn, M. y Sandine, W.E. (1979).- "Vitamin B., and ascorbic acid in kimchi inoculated with Propionibacterium treudenreichii ss. sherma nii".- J. Food Sci. 44, 873-877.

37. Rodriguez de la Borbolla y Alcalá, J. M.a y Rejano Navarro, L. (1981)."Sobre la preparación de la aceituna estilo sevillano. La fermentación. II".Grasas y Aceites 32, 103-113.

38. Rose, A.H. (1969).- "Microbiologia quimica".- Ed. Alhambra, Madrid.

39. Sánchez, A.H.; Castro, A. de y Rejano, L. (1992).- "Controlled fermentation of caperberries".- J. Food Sci. 57, 675-678.

40. Taylor, S.L.; Leatherwood, M. y Lieber, E.R. (1978).- 'Histamine in sauerkraut".- J. Food Sci. 43, 1.030-1.032.

41. Vázquez Roncero, A. (1965).- "Química del olivo III. Los componentes orgánicos (3." parte)".- Grasas y Aceites 16, 292-304.

(Recibido: Abril 1992) 